DA SILVA PAIVA, Francisco Cleiton. Tributação ambiental como mecanismo indutor do direito humano ao desenvolviento sustentável. Revista Eletrônica Direito e Política, Programa de PósGraduação Stricto Sensu em Ciência Jurídica da UNIVALI, Itajaí, v.14, n.1, 10 quadrimestre de 2019. Disponível em: www.univali.br/direitoepolitica - ISSN 1980-7791

\title{
TRIBUTAÇÃO AMBIENTAL COMO MECANISMO INDUTOR DO DIREITO HUMANO AO DESENVOLVIENTO SUSTENTÁVEL
}

\author{
ENVIRONMENTAL TAXATION AS MECHANISM INDUCING HUMAN RIGHTS TO \\ SUSTAINABLE DEVELOPMENT
}

Francisco Cleiton da Silva Paiva ${ }^{1}$

\begin{abstract}
RESUMO
Este trabalho tem por objetivo mostrar a tributação ambiental como instrumento indutor da proteção ao meio ambiente e alcance do direito humano ao desenvolvimento sustentável. Como agente responsável pela promoção do desenvolvimento sustentável, o Poder Público tem a prerrogativa de contribuir positivamente para um meio ambiente ecologicamente equilibrado, via instituição de tributos. O direito ao meio ambiente é parte fundamental para a qualidade de vida e dignidade da pessoa humana, sendo este um direito transindividual. A pesquisa corresponde a um estudo bibliográfico, de natureza qualitativa e objetivo descritivo. Com ela verificou-se que a proteção ambiental é fator decisivo para a consolidação do direito humano ao desenvolvimento sustentável, visto que o indivíduo precisa da natureza para se desenvolver plenamente em sua condição de vida, tendo a tributação ecológica um papel fundamental na promoção desse direito, tão importante para as atuais e futuras gerações.
\end{abstract}

PALAVRAS-CHAVE: Direitos Humanos; Meio Ambiente; Tributação Ambiental; Sustentabilidade.

\section{ABSTRACT}

The objective of this work is to show environmental taxation as an instrument that promotes the protection of the environment and the scope of the human right to sustainable development. As an agent responsible for promoting sustainable development, the Public Power has the prerogative to contribute positively to an ecologically balanced environment, through the institution of taxes. The right to the environment is a fundamental part of the quality of life and dignity of the human being, which is a transindividual right. The research corresponds to a bibliographic study, of qualitative nature and descriptive objective. It was verified that environmental protection is a decisive factor for the consolidation of the human right to sustainable development, since the individual needs nature to fully develop in his or her living condition, and

\footnotetext{
1 Mestre em Ambiente, Tecnologia e Sociedade (UFERSA), Especialista em Contabilidade Pública (FINOM), Graduado em Ciências Contábeis (UERN), Graduando em Direito (UFCG). Contabilista e Gestor Financeiro do Campus Pau dos Ferros da Universidade Federal Rural do Semi-Árido (UFERSA). Pau dos Ferros-RN/Brasil. E-mail: cleiton_paiva@hotmail.com
} 
DA SILVA PAIVA, Francisco Cleiton. Tributação ambiental como mecanismo indutor do direito humano ao desenvolviento sustentável. Revista Eletrônica Direito e Política, Programa de PósGraduação Stricto Sensu em Ciência Jurídica da UNIVALI, Itajaí, v.14, n.1, 10 quadrimestre de 2019. Disponível em: www.univali.br/direitoepolitica - ISSN 1980-7791

ecological taxation plays a fundamental role in promoting this right, so important for the present and future generations.

KEYWORDS: Human Rights; Environment; Environmental Taxation; Sustainability.

\section{INTRODUÇÃo}

As ações do homem para com o meio ambiente têm provocado sérias mudanças no planeta e ocasionando diversos problemas, cujos efeitos atingem e são sentidos em todas as partes do mundo. Por essa razão, as discussões acerca da questão ambiental têm ganhado força, ao mesmo tempo em que se insere como pauta das ações do Estado quando da definição das políticas públicas. Alguns fatores como a intensificação da industrialização, explosão demográfica, aumento da produção, consumo desenfreado, urbanização e modernização das técnicas agrícolas trouxeram consigo também consequências como a degradação dos recursos naturais, poluição da água, do solo e do ar, que culminaram em desastres ambientais observados até os dias de hoje². Em função dessas questões, tem-se buscado estabelecer uma nova forma de desenvolvimento, provocando uma melhora na qualidade de vida da população e, ao mesmo tempo, a sobrevivência das espécies no planeta.

Não por acaso, abordando a temática ambiental, Leonardo Boff ${ }^{3}$ observa que, nos dias de hoje, o tema sustentabilidade e meio ambiente é um dos assuntos mais comentados em todo o mundo, mostrando a importância que o tema tem alcançado perante a sociedade, as empresas e os governos. Isso vem acontecendo não só devido a um afloramento de uma percepção de limitação dos recursos naturais (que já é evidente e que vem se consolidando cada dia mais), mas também pelo entendimento que um meio ambiente é um bem que deve estar disponível a todas as pessoas de modo indistinto, inclusive numa perspectiva atemporal.

\footnotetext{
2 NASCIMENTO, Luis Felipe; LEMOS, Ângela Denise da Cunha; MELLO, Maria Celina Abreu de.

Gestão Socioambiental Estratégica. Porto Alegre: Bookman, 2008, p. 57.
}

3 BOFF, Leonardo. Sustentabilidade: o que é, o que não é. Petrópoles-RJ: Vozes, 2012. 
DA SILVA PAIVA, Francisco Cleiton. Tributação ambiental como mecanismo indutor do direito humano ao desenvolviento sustentável. Revista Eletrônica Direito e Política, Programa de PósGraduação Stricto Sensu em Ciência Jurídica da UNIVALI, Itajaí, v.14, n.1, $1^{\circ}$ quadrimestre de 2019. Disponível em: www.univali.br/direitoepolitica - ISSN 1980-7791

No Brasil, o Poder Público encarrega-se da responsabilidade compartilhada de defender e preservar o meio ambiente, garantindo, assim, o desenvolvimento sustentável no âmbito nacional, conforme definido na Constituição Federal de 1988, no Capítulo VI, que trata do Meio Ambiente, assim como em outros dispositivos do texto constitucional.

Viver em um ambiente preservado, com qualidade de vida e em condições que beneficiem a saúde das pessoas é um direito humano. Contudo, diante do contexto ambiental atual, como o Estado poderia atuar para beneficiar e promover um meio ambiente equilibrado e capaz de atender às necessidades da atual e futura geração, garantindo assim esse direito à população?

O presente trabalho objetiva mostrar a tributação ambiental como instrumento indutor da proteção ao meio ambiente e para alcance do direito humano ao desenvolvimento sustentável. Neste sentido, é importante que se compreenda a dimensão do meio ambiente relacionada aos direitos humanos, haja vista que, comumente, tem-se uma percepção equivocada de que direitos humanos estão mais ligados a outros aspectos, como direitos dos presos, dentre outros direitos civis, entendimento esse que não traduz seu conceito. Por isso, tornam-se importantes outras abordagens envolvendo os Direitos Humanos em suas várias dimensões. Além disso, não há como tratar da vida humana sem considerar a variável ambiental, fundamento de sua própria existência.

Quanto ao aspecto metodológico, este artigo corresponde a um estudo de revisão. Está categorizado, quanto à sua natureza, como pesquisa qualitativa; quanto aos objetivos da pesquisa, definida como descritiva; e, quanto ao objeto, considerada uma pesquisa bibliográfica.

\section{DIREITOS HUMANOS}

O jurista Fábio Conder Comparato define os Direitos Humanos como os direitos fundamentais da pessoa humana, contemplando não só os aspectos individuais 
DA SILVA PAIVA, Francisco Cleiton. Tributação ambiental como mecanismo indutor do direito humano ao desenvolviento sustentável. Revista Eletrônica Direito e Política, Programa de PósGraduação Stricto Sensu em Ciência Jurídica da UNIVALI, Itajaí, v.14, n.1, 10 quadrimestre de 2019. Disponível em: www.univali.br/direitoepolitica - ISSN 1980-7791

como também seu sentido comunitário, chamados de direitos de fraternidade. ${ }^{4}$ Por sua vez, Carvalho Ramos entende que os Direitos Humanos "consistem em um conjunto de direitos considerado indispensável para uma vida humana, pautada na liberdade, igualdade e dignidade. Os direitos humanos são os direitos essenciais e indispensáveis à vida digna". ${ }^{5}$

Direitos Humanos são direitos vinculados à condição da pessoa humana, entendendo-se que sem esses direitos o ser humano "não consegue existir ou não é capaz de se desenvolver e de participar plenamente da vida". ${ }^{6}$ Embora não exista um rol determinado de direitos que o ser humano precise dispor para que tenha uma vida digna (já que as necessidades humanas variam conforme o contexto histórico e cultural), há elementos que, ao longo do tempo, foram sendo incorporados dentro do que é considerado essencial para que o mesmo se desenvolva plenamente. Historicamente, esses direitos são marcados pela mutação e constante renovação, desde a Antiguidade aos dias de hoje, podendo ser considerado um produto da História.

Os Direitos Humanos são classificados em primeira, segunda e terceira geração (ou dimensão), correspondendo, respectivamente, aos direitos à liberdade, igualdade e fraternidade, basicamente o mesmo lema da Revolução Francesa de 1789, teoria defendida por Karel Vasak, em 1979. ${ }^{7}$

Nessa linha, Carvalho Ramos explica que os direitos de "primeira dimensão" correspondem aos direitos de liberdade, que são os individuais, civis e políticos. Os de "segunda dimensão" são aqueles ligados aos direitos de igualdade, quer sejam econômicos, sociais e culturais, por exemplo. ${ }^{8}$

\footnotetext{
${ }^{4}$ COMPARATO, Fábio Konder. A afirmação histórica dos Direitos Humanos. São Paulo: Saraiva, 2001, p. 50.

${ }^{5}$ RAMOS, André de Carvalho. Curso de direitos humanos. São Paulo: Saraiva, 2014, p. 23.

${ }^{6}$ RAMOS, André de Carvalho. Teoria geral dos direitos humanos na ordem internacional. 5. ed. São Paulo: Saraiva, 2015, p. 38

7 FERREIRA FILHO, Manoel Gonçalves. Direitos Humanos Fundamentais. São Paulo: Saraiva, 2011, p. 57.

${ }^{8}$ RAMOS, André de Carvalho. Curso de direitos humanos. São Paulo: Saraiva, 2014, p. 49.
} 
DA SILVA PAIVA, Francisco Cleiton. Tributação ambiental como mecanismo indutor do direito humano ao desenvolviento sustentável. Revista Eletrônica Direito e Política, Programa de PósGraduação Stricto Sensu em Ciência Jurídica da UNIVALI, Itajaí, v.14, n.1, 10 quadrimestre de 2019. Disponível em: www.univali.br/direitoepolitica - ISSN 1980-7791

Os direitos classificados como de "terceira dimensão" (ou geração) são os direitos de titularidade da comunidade (solidariedade e fraternidade), que estão ligados à qualidade de vida e solidariedade entre os seres humanos, abrangendo os direitos relativos à paz, ao desenvolvimento, ao patrimônio comum da humanidade e ao meio ambiente.

Há ainda uma outra corrente doutrinária, defendida por Bonavides, que preconiza a existência de mais duas outras dimensões, quais sejam: uma "quarta dimensão" dos direitos humanos (que ele defende corresponder aos direitos de informação, pluralismo e à democracia) e também de um grupo de quinta dimensão (que corresponde no direito fundamental à paz). ${ }^{9}$ Outra corrente, mais além, defende que há também uma "sexta dimensão", que é o direito humano à água potável. ${ }^{10}$

Um marco histórico para os direitos humanos ocorreu em 1948, com a proclamação da "Declaração Universal dos Direitos Humanos" pela Organização das Nações Unidas (ONU), uma conquista enorme para a humanidade no tocante aos seus direitos individuais e universais. Dentre todos os direitos postos a partir do documento, o mesmo trouxe em seu Art. $3^{\circ}$ que o ser humano tem direito à "vida", considerando que nela estão incluídas as condições necessárias à sua manutenção. ${ }^{11}$ Dentre essas condições está a preservação do meio ambiente, pressuposto fundamental, sem o qual, inclusive, não seria possível a vida.

À luz da contemporaneidade, é interessante observar na Declaração dos Direitos Humanos de 1948 que nela não há nenhuma menção sobre o meio ambiente. Isso mostra que assuntos ligados ao meio ambiente, à época da sua elaboração, ainda não eram tratados com a devida importância, ou, no mínimo, não estava em evidência. Qual a razão disso? O meio ambiente ainda não era considerado como um bem a ser preservado nem um problema a ser resolvido.

\footnotetext{
9 BONAVIDES, Paulo. Curso de Direito Constitucional. 24. ed. São Paulo: Malheiros Editores, 2009 , p. 579.

${ }^{10}$ FACHIN, Zulmar; SILVA, Deise Marcelino da. Acesso à agua potável: direito fundamental de sexta geração. São Paulo: Millennium, 2010, p. 06.

${ }^{11}$ ONU - Organização das Nações Unidas. Declaração Universal dos Direitos Humanos - 1948. Rio de Janeiro: UNIC, 2009.
} 
DA SILVA PAIVA, Francisco Cleiton. Tributação ambiental como mecanismo indutor do direito humano ao desenvolviento sustentável. Revista Eletrônica Direito e Política, Programa de PósGraduação Stricto Sensu em Ciência Jurídica da UNIVALI, Itajaí, v.14, n.1, 10 quadrimestre de 2019. Disponível em: www.univali.br/direitoepolitica - ISSN 1980-7791

\section{MEIO AMBIENTE E DESENVOLVIMENTO SUSTENTÁVEL}

Mais de setenta anos depois, o que se nota é a questão ambiental ganhando destaque nas discussões em todo planeta, visto que o ser humano tem percebido o quanto o desgaste do meio natural atinge diretamente suas vidas. A concepção de que os recursos naturais são limitados e cada vez mais em declínio acendeu o sinal de alerta para que as pessoas passassem a adotar uma nova postura e uma nova mentalidade em relação ao meio ambiente, entendendo que a destruição da natureza é, automaticamente, a destruição do próprio ser humano.

A concepção de limitação dos recursos naturais fez emergir a necessidade da busca pelo equilíbrio entre a utilização do meio ambiente como fonte de riqueza e o desenvolvimento econômico e social. A sustentabilidade surge como condição fundamental para a manutenção da própria vida na Terra e tem como ideia básica assegurar "que nossas ações de hoje não limitarão a gama de opções econômicas, sociais e ambientais disponíveis para as gerações futuras". ${ }^{12}$

Manter o meio ambiente em equilíbrio é condição para o desenvolvimento pleno de todas as sociedades. Uma sociedade sadia e equilibrada é aquela que entende que seu bem-estar é alcançado quando se considera nas suas ações não só os impactos que elas podem causar no presente, mas, também, os efeitos que essas ações podem gerar no futuro. Esse é o conceito de "Desenvolvimento Sustentável", definido pelo relatório "Nosso Futuro Comum" (também conhecido como Relatório Brundtland, da Comissão Mundial sobre o Meio Ambiente e Desenvolvimento, da ONU, em 1987), como "a habilidade das sociedades para satisfazer às necessidades do presente sem comprometer a possibilidade das futuras gerações de atenderem a suas próprias necessidades". ${ }^{13}$

No entanto, esse entendimento já vinha sendo firmado desde 1972, a partir da Conferência das Nações Unidas sobre o Meio Ambiente Humano, da qual resultou a Declaração de Estocolmo e o Programa das Nações Unidas para o Meio

\footnotetext{
12 ELKINGTON, John. Sustentabilidade, canibais com garfo e faca. São Paulo: M. Books do Brasil Editora Ltda., 2012, p. 52.

${ }^{13}$ CMMAD, Comissão Mundial Sobre Meio Ambiente e Desenvolvimento. Nosso Futuro Comum. Rio de Janeiro: Fundação Getúlio Vargas, 1999, p. 09.
} 
DA SILVA PAIVA, Francisco Cleiton. Tributação ambiental como mecanismo indutor do direito humano ao desenvolviento sustentável. Revista Eletrônica Direito e Política, Programa de PósGraduação Stricto Sensu em Ciência Jurídica da UNIVALI, Itajaí, v.14, n.1, 10 quadrimestre de 2019. Disponível em: www.univali.br/direitoepolitica - ISSN 1980-7791

Ambiente (PNUMA). Essa declaração foi também um marco histórico para o Direito Ambiental ao considerar o direito ao meio ambiente como um direito fundamental do indivíduo, equiparando-o a direitos já consolidados na esfera dos direitos humanos, como a liberdade e igualdade (primeira e segunda dimensão). No documento consta em seu Princípio no 1 que: "o ser humano tem o direito fundamental à liberdade, à igualdade e ao desfrute de condições de vida adequada em um meio cuja qualidade lhe permita levar uma vida digna e gozar de bem-estar, e tem a solene obrigação de proteger e melhorar esse meio para as gerações presentes e futuras". ${ }^{14}$

A referida Declaração defende também que quando existe uma relação em que o homem protege a natureza, ambos são beneficiados, destacando em seu Preâmbulo: "O homem é ao mesmo tempo obra e construtor do meio ambiente que o cerca, o qual lhe dá sustento material e lhe oferece oportunidade para desenvolver-se intelectual, moral, social e espiritualmente". O mesmo texto ressalta ainda que: "a proteção e o melhoramento do meio ambiente humano é uma questão fundamental que afeta o bem-estar dos povos e o desenvolvimento econômico do mundo inteiro, um desejo urgente dos povos de todo o mundo e um dever de todos os governos" (ONU, 1972, s.I. ). ${ }^{15}$

Quando o conceito de desenvolvimento sustentável aborda a questão das "necessidades", Dias (2011) explica que o desenvolvimento sustentável é, antes de qualquer coisa, um projeto social e político destinado a erradicar a pobreza, elevar a qualidade de vida da sociedade e satisfazer às necessidades básicas da humanidade. Portanto, a proteção do meio ambiente emerge como um direito humano, cuja responsabilidade é de todos e global, o que inclui os Governos, as organizações e a sociedade de modo geral.

14 ONU - Organização das Nações Unidas. DECLARAÇÃo SOBRE MEIO AMBIENTE HUMANO (DECLARAÇÃO DE ESTOCOLMO) - 1972, s.I. Disponível em: < https://nacoesunidas.org/acao/meio-ambiente/> Acesso em 01 out. 2018.

15 ONU - Organização das Nações Unidas. DECLARAÇÃo SOBRE MEIO AMBIENTE HUMANO (DECLARAÇÃO DE ESTOCOLMO) - 1972, s.I. Disponível em: <

https://nacoesunidas.org/acao/meio-ambiente/> Acesso em 01 out. 2018. 
DA SILVA PAIVA, Francisco Cleiton. Tributação ambiental como mecanismo indutor do direito humano ao desenvolviento sustentável. Revista Eletrônica Direito e Política, Programa de PósGraduação Stricto Sensu em Ciência Jurídica da UNIVALI, Itajaí, v.14, n.1, 10 quadrimestre de 2019. Disponível em: www.univali.br/direitoepolitica - ISSN 1980-7791

O desenvolvimento pleno do ser humano depende de vários fatores, a fim de que possa encontrar a condição adequada para uma vida com dignidade. A ONU, ao desenvolver o conceito de desenvolvimento sustentável, traz com isso uma tentativa de resposta para os problemas ambientais existentes e dos riscos que todo o planeta corre em função dessa problemática.

Embora pareça fácil, lidar com a questão ambiental não é tão simples assim. A própria dinâmica econômica (ligada diretamente à utilização de recursos naturais) tem que ser levada em conta, já que ações de impacto econômico trazem, por consequência, um impacto socioambiental imediato. Ou seja, economia, sociedade e meio ambiente encontram-se em uma relação direta e intimamente ligados. Questões inerentes ao contexto emergem a partir disso, como, por exemplo: é possível reduzir o desgaste na natureza sem afetar a economia? É possível mexer na economia sem atingir a sociedade? O fato é que é impossível mexer nessas questões sem impactar na vida humana, nas condições de vida da sociedade e no bem-estar dos indivíduos, não podendo ser analisado nenhum ponto sem uma abordagem holística.

Por isso, "para ser sustentável o desenvolvimento deve ser economicamente viável, socialmente justo e ambientalmente correto", como afirma Boff'16, conceito também defendido por Elkington"17, conhecido como "Tripé da Sustentabilidade" (Triple Bottom Line), que preconiza exatamente o equilíbrio entre essas três variáveis. De maneira similar, a própria Declaração de Estocolmo (1972) traz também que: "O desenvolvimento econômico e social é indispensável para assegurar ao homem um ambiente de vida e trabalho favorável $[\ldots]^{\prime \prime}$ (Princípio no 8$)^{18}$, ensejando também esse conceito.

\footnotetext{
${ }^{16}$ BOFF, Leonardo. Sustentabilidade: o que é, o que não é. Petrópoles-RJ: Vozes, 2012, p. 43. 17 ELKINGTON, John. Sustentabilidade, canibais com garfo e faca. São Paulo: M. Books do Brasil Editora Ltda., 2012.
}

18 ONU - Organização das Nações Unidas. DECLARAÇÃo SOBRE MEIO AMBIENTE HUMANO (DECLARAÇÃO DE ESTOCOLMO) - 1972, s.I.. Disponível em: <

https://nacoesunidas.org/acao/meio-ambiente/> Acesso em 01 out. 2018. 
DA SILVA PAIVA, Francisco Cleiton. Tributação ambiental como mecanismo indutor do direito humano ao desenvolviento sustentável. Revista Eletrônica Direito e Política, Programa de PósGraduação Stricto Sensu em Ciência Jurídica da UNIVALI, Itajaí, v.14, n.1, 10 quadrimestre de 2019. Disponível em: www.univali.br/direitoepolitica - ISSN 1980-7791

Viver em um ambiente preservado, com qualidade de vida e em condições que beneficiem a saúde das pessoas é um direito humano. No Brasil, a Constituição Federal de 1988 aborda em seu Capítulo VI o Meio ambiente, que, em seu Art. 225 declara que: "Todos têm direito ao meio ambiente ecologicamente equilibrado, bem de uso comum do povo e essencial à sadia qualidade de vida, impondo-se ao Poder Público e à coletividade o dever de defendê-lo e preservá-lo para as presentes e futuras gerações."19 Essa posição compartilha a responsabilidade pela garantia dos direitos ambientais não só para o governo, como também com a própria sociedade, que é, ao mesmo tempo, agente transformador do meio ambiente e também quem é suscetível nessa transformação.

\section{TRIBUTAÇÃO AMBIENTAL}

Atualmente, uma das formas que o Estado dispõe para contribuir para a preservação do meio ambiente, ao mesmo tempo proporcionando à sociedade o direito ao desenvolvimento sustentável, é por meio da instituição de tributos, cujas receitas podem ser utilizadas para a preservação e promoção do meio ambiente, como os denominados tributos ambientais (também conhecidos como tributos ecológicos), que fazem parte da chamada economia verde.

Tributos são instrumentos que o Estado dispõe para obtenção de receitas, buscando, a partir delas, a devida aplicação para a prestação de serviços e desenvolvimento de políticas públicas de interesse de toda sociedade. O Código Tributário Nacional, em seu art. 30 dispõe que: "Tributo é toda prestação pecuniária compulsória, em moeda e cujo valor nela se possa exprimir, que não constitua sanção de ato ilícito, instituída em lei e cobrada mediante atividade administrativa plenamente vinculada".

\footnotetext{
19 BRASIL. Constituição da República Federativa do Brasil de 1988. Disponível em: < https://www.planalto.gov.br/ccivil_03/constituicao/constituicao.htm> Acesso em: 01 out. 2018.
} 
DA SILVA PAIVA, Francisco Cleiton. Tributação ambiental como mecanismo indutor do direito humano ao desenvolviento sustentável. Revista Eletrônica Direito e Política, Programa de PósGraduação Stricto Sensu em Ciência Jurídica da UNIVALI, Itajaí, v.14, n.1, 10 quadrimestre de 2019. Disponível em: www.univali.br/direitoepolitica - ISSN 1980-7791

O desenvolvimento nacional, preconizado no art. $3^{\circ}$ da Constituição Federal, não será de outro modo atingido sem que seja considerada a variável ambiental, esculpida nos Arts. 170 e 225 da nossa Constituição, premissa básica do desenvolvimento sustentável. Por sua vez, é papel do Poder Público contribuir positivamente para um meio ambiente ecologicamente equilibrado, via aplicação de recursos ou incentivos fiscais, já que o Estado pode atuar e interferir na economia por meio da instituição de tributos, sejam eles com funções fiscais, parafiscais ou extrafiscais.

Os tributos com função fiscal são aqueles usados para obter recursos orçamentários para a entidade estatal correspondente, como, por exemplo, o caso do IPTU cobrado pelos municípios. Os parafiscais são aqueles utilizados para obtenção de recursos para orçamentos de entidades que funcionam como "prolongamentos" do Estado, mas que não se confundem com o mesmo, a exemplo dos Conselhos de Regulamentação Profissional, os denominados Conselhos de Classe. Por fim, os tributos com função extrafiscal são aqueles instituídos com objetivos que vão além da própria arrecadação. Podem ser utilizados de várias formas, desde o incentivo à determinadas condutas e atividades para a consecução de finalidades específicas, até para o alcance de resultados no intuito de alcançar a redução de externalidades negativas (como é o caso da preservação ou conservação do meio ambiente, bem como a mitigação dos impactos negativos sofridos), como parte de uma política pública de desenvolvimento sócio-econômico-ambiental. ${ }^{20}$

No caso da utilização de instrumentos tributários para finalidade extrafiscal de corrigir, minimizar ou mesmo promover a proteção do meio ambiente, esta é uma forma de indução do desenvolvimento nacional por meio de uma política tributária ambiental.

\footnotetext{
20 MACHADO SEGUNDO, Hugo de Brito. Manual de Direito Tributário. 10. ed. edição, rev., atual. e ampl. São Paulo: Atlas, 2018, p. 64.
} 
DA SILVA PAIVA, Francisco Cleiton. Tributação ambiental como mecanismo indutor do direito humano ao desenvolviento sustentável. Revista Eletrônica Direito e Política, Programa de PósGraduação Stricto Sensu em Ciência Jurídica da UNIVALI, Itajaí, v.14, n.1, 10 quadrimestre de 2019. Disponível em: www.univali.br/direitoepolitica - ISSN 1980-7791

Na análise do art. 170, Inciso VI, da Constituição Federal, que trata da Ordem Econômica e Financeira, pode ser observado que para assegurar a todos uma existência digna, direito humano fundamental, há que ser considerado como princípio básico a variável ambiental:

Art. 170. A ordem econômica, fundada na valorização do trabalho humano e na livre iniciativa, tem por fim assegurar a todos existência digna, conforme os ditames da justiça social, observados os seguintes princípios:

$[\ldots]$

VI - defesa do meio ambiente, inclusive mediante tratamento diferenciado conforme o impacto ambiental dos produtos e serviços e de seus processos de elaboração e prestação; ${ }^{21}$

Percebe-se que o Estado brasileiro teve como preocupação estabelecer na sua Constituição princípios norteadores do desenvolvimento sustentável como pilares da sociedade, considerando que o meio ambiente ecologicamente equilibrado é essencial para o alcance desse desenvolvimento. Essa é uma preocupação imbuída do espírito de solidariedade/fraternidade estampados no próprio Preâmbulo da Carta Maior brasileira, pois o desenvolvimento sustentável preocupa-se não somente com o hoje, mas também com as gerações futuras e seu bem-estar.

É com o propósito de preservar o meio ambiente e promover um desenvolvimento capaz de proporcionar uma qualidade de vida para toda a sociedade, que surgiu a Tributação Ambiental, atuando precipuamente com a extrafiscalidade, punindo aqueles que atuam negativamente em relação ao meio ambiente e premiando aqueles que adotam posturas positivas de preservação/conservação do meio natural.

A Tributação Ambiental é entendida como "o emprego de instrumentos tributários para orientar o comportamento dos contribuintes a protesto do meio ambiente, bem como para gerar recursos necessários à prestação de serviços

${ }^{21}$ BRASIL. Constituição da República Federativa do Brasil de 1988. Disponível em: < https://www.planalto.gov.br/ccivil_03/constituicao/constituicao.htm> Acesso em: 01 out. 2018. 
DA SILVA PAIVA, Francisco Cleiton. Tributação ambiental como mecanismo indutor do direito humano ao desenvolviento sustentável. Revista Eletrônica Direito e Política, Programa de PósGraduação Stricto Sensu em Ciência Jurídica da UNIVALI, Itajaí, v.14, n.1, 10 quadrimestre de 2019. Disponível em: www.univali.br/direitoepolitica - ISSN 1980-7791

públicos de natureza ambiental". ${ }^{22}$ Neste sentido, o Estado deve atuar para a implantação, fiscalização e aplicação dos "tributos ambientais", onde pode serem citados como exemplos o "ICMS Ecológico" e o "IPTU Verde", já adotados em vários estados e municípios do país, e que compõem os chamados "impostos verdes".

O "ICMS Ecológico", por exemplo, é um tipo de intercâmbio entre os estados e municípios, em que parte dos recursos arrecadados pelo estado com o ICMS (Impostos sobre Circulação de Mercadorias e Serviços) é transferido aos municípios, por meio de quotas. Dessa forma, 25\% da arrecadação retorna para os municípios (aqueles que se adequam às normas de repasse), em troca de ações a serem desenvolvidas em prol do meio ambiente. ${ }^{23}$

O "IPTU Verde", por sua vez, varia de acordo com cada município instituidor, a atua com o objetivo de estimular ações de preservação ambiental, mediante benefícios fiscais, como a redução de alíquota do imposto para aqueles contribuintes que realizam tais ações, como, por exemplo, plantação e manutenção de árvores na calçada dos prédios e residências, assim como o uso de equipamentos que visem à preservação/conservação do meio ambiente, tais como os que economizam água.

\section{CONSIDERAÇÕES FINAIS}

Os Direitos Humanos englobam uma série de direitos, que vão desde o direito à vida, liberdade, igualdade, até temas como o meio ambiente. Classificados em três categorias, denominadas de "dimensões" ou "gerações", o meio ambiente encontrasse na terceira dimensão desses direitos.

\footnotetext{
22 COSTA, Regina Helena. Apontamento sobre a tributação ambiental no Brasil. In: TORRES, Heleno Taveira (coord.). Direito Tributário Ambiental. São Paulo:

Malheiros, 2005, p. 293.

${ }^{23}$ LOUREIRO, Wilson. ICMS Ecológico, uma experiência brasileira de pagamentos por serviços ambientais. São Paulo: Fundação SOS Mata Atlântica, 2008, p. 20.
} 
DA SILVA PAIVA, Francisco Cleiton. Tributação ambiental como mecanismo indutor do direito humano ao desenvolviento sustentável. Revista Eletrônica Direito e Política, Programa de PósGraduação Stricto Sensu em Ciência Jurídica da UNIVALI, Itajaí, v.14, n.1, $1^{\circ}$ quadrimestre de 2019. Disponível em: www.univali.br/direitoepolitica - ISSN 1980-7791

A proteção do meio ambiente, como condição essencial para o direito à vida, coloca esse direito como parte daqueles que alicerçam os direitos humanos.

Ter um ambiente ecologicamente equilibrado e protegido é fundamental para o desenvolvimento econômico, que, por sua vez, é necessário para que a sociedade também se desenvolva em sua plenitude e usufrua de um bem-estar.

É a partir do equilíbrio entre as variáveis econômica, ecológica e social que se tem o desenvolvimento sustentável, resultado conjunto de ações de todas as esferas sociais e cujos benefícios são sentidos não só pelas gerações presentes, mas também pelas futuras gerações.

A responsabilidade pelo desenvolvimento sustentável é compartilhada entre vários agentes, como as empresas, a sociedade e os governos. No Brasil, o Poder Público é um dos responsáveis para que todos tenham garantidos o direito ao meio ambiente ecologicamente equilibrado, sendo este considerado um bem de uso comum do povo e essencial à sadia qualidade de vida, cabendo ao Estado e à coletividade o dever de defendê-lo e preservá-lo para a presente e futuras gerações.

Neste trabalho, o objetivo foi mostrar a tributação ambiental como instrumento indutor da proteção ao meio ambiente e alcance do direito humano ao desenvolvimento sustentável. Com efeito, foi apresentado que a tributação ecológica tem um papel muito importante para a preservação do meio ambiente e para a garantia do direito humano ao desenvolvimento sustentável, e isso ocorre por meio da aplicação das receitas auferidas pelo Estado com esses tipos de tributos.

Por fim, percebe-se que no Brasil as ações que envolvem a busca pela promoção e proteção do meio ambiente ainda são incipientes, carecendo de ampliação e aplicação por parte do Estado, visto que não é tarefa fácil destinar recursos para uma área que, apesar de ser evidente sua importância, é uma percepção que não atingiu toda sociedade, ainda. Muitas variáveis influem nesse cenário, como o nível de instrução da população, em que mostra que, quanto maior a educação, maior preocupação com o meio ambiente. Isso ainda é um desafio 
DA SILVA PAIVA, Francisco Cleiton. Tributação ambiental como mecanismo indutor do direito humano ao desenvolviento sustentável. Revista Eletrônica Direito e Política, Programa de PósGraduação Stricto Sensu em Ciência Jurídica da UNIVALI, Itajaí, v.14, n.1, $1^{\circ}$ quadrimestre de 2019. Disponível em: www.univali.br/direitoepolitica - ISSN 1980-7791

para o Brasil, já que uma população bem informada é mais capaz de exigir do Poder Público ações dessa natureza. E, se o Estado pode ser indutor dessas ações, a própria sociedade também pode, ou mais ainda, já que, conforme o próprio da Constituição Federal, Art. 10, parágrafo único, "Todo poder emana do povo $[\ldots]^{\prime 24}$, e ninguém melhor que o próprio povo para defender seus direitos.

\section{REFERÊNCIAS DAS FONTES CITADAS}

ANDRADE, Maria Margarida de. Introdução à metodologia do trabalho científico: elaboração de trabalhos na graduação. 8. ed. São Paulo: Atlas, 2007.

BOFF, Leonardo. Sustentabilidade: o que é, o que não é. Petrópoles-RJ: Vozes, 2012.

BONAVIDES, Paulo. Curso de Direito Constitucional. 24. ed. São Paulo: Malheiros Editores, 2009.

BRASIL. Código Tributário Nacional. In Vade Mecum. São Paulo: Saraiva, 2018.

BRASIL. Constituição da República Federativa do Brasil de 1988. Disponível em:

https://www.planalto.gov.br/ccivil 03/constituicao/constituicao.htm> Acesso em: 01 out. 2018.

CMMAD, Comissão Mundial Sobre Meio Ambiente e Desenvolvimento. Nosso Futuro Comum. Rio de Janeiro: Fundação Getúlio Vargas, 1991.

COMPARATO, Fábio Konder. A afirmação histórica dos Direitos Humanos. São Paulo: Saraiva, 2001.

24 BRASIL. Constituição da República Federativa do Brasil de 1988. Disponível em: < https://www.planalto.gov.br/ccivil 03/constituicao/constituicao.htm> Acesso em: 01 out. 2018. 
DA SILVA PAIVA, Francisco Cleiton. Tributação ambiental como mecanismo indutor do direito humano ao desenvolviento sustentável. Revista Eletrônica Direito e Política, Programa de PósGraduação Stricto Sensu em Ciência Jurídica da UNIVALI, Itajaí, v.14, n.1, $1^{\circ}$ quadrimestre de 2019. Disponível em: www.univali.br/direitoepolitica - ISSN 1980-7791

COSTA, Regina Helena. Apontamento sobre a tributação ambiental no Brasil. In: TORRES, Heleno Taveira (coord.). Direito Tributário Ambiental. São Paulo: Malheiros, 2005.

DIAS, Reinaldo. Gestão ambiental: responsabilidade social e sustentabilidade. 2. ed. São Paulo: Atlas, 2011.

ELKINGTON, John. Sustentabilidade, canibais com garfo e faca. São Paulo: M. Books do Brasil Editora Ltda., 2012.

FERREIRA FILHO, Manoel Gonçalves. Direitos Humanos Fundamentais. São Paulo: Saraiva, 2011.

LOUREIRO, Wilson. ICMS Ecológico, uma experiência brasileira de pagamentos por serviços ambientais. São Paulo: Fundação SOS Mata Atlântica, 2008.

MACHADO SEGUNDO, Hugo de Brito. Manual de Direito Tributário. 10. ed. edição, rev., atual. e ampl. São Paulo: Atlas, 2018.

ONU - Organização das Nações Unidas. Declaração Universal dos Direitos Humanos - 1948. Rio de Janeiro: UNIC, 2009.

ONU - Organização das Nações Unidas. DECLARAÇÃo SOBRE MEIO AMBIENTE hUMANO (DECLARAÇÃO DE ESTOCOLMO) - 1972. Disponível em: < https://nacoesunidas.org/acao/meio-ambiente/> Acesso em 01 out. 2018.

NASCIMENTO, Luis Felipe; LEMOS, Ângela Denise da Cunha; MELLO, Maria Celina Abreu de. Gestão Socioambiental Estratégica. Porto Alegre: Bookman, 2008.

RAMOS, André de Carvalho. Curso de direitos humanos. São Paulo: Saraiva, 2014. 
DA SILVA PAIVA, Francisco Cleiton. Tributação ambiental como mecanismo indutor do direito humano ao desenvolviento sustentável. Revista Eletrônica Direito e Política, Programa de PósGraduação Stricto Sensu em Ciência Jurídica da UNIVALI, Itajaí, v.14, n.1, $1^{\circ}$ quadrimestre de 2019. Disponível em: www.univali.br/direitoepolitica - ISSN 1980-7791

RAMOS, André de Carvalho. Teoria geral dos direitos humanos na ordem internacional. 5. ed. São Paulo: Saraiva, 2015.

SANTOS, Boaventura de Souza. Crítica da razão indolente: contra o desperdício da experiência. 3. ed. São Paulo: Cortez, 2001.

RECIBIDO EM: 03/12/2018

APROVADO EM: 27/04/2019 